\title{
MODELLING COMBUSTION IN SPARK IGNITION ENGINES WITH SPECIAL EMPHASIS ON NEAR WALL FLAME QUENCHING
}

\author{
C.P. Ranasinghe ${ }^{1^{*}}$ and W. Malalasekera ${ }^{2}$ \\ 1. Department of Mechanical Engineering, University of Moratuwa \\ Sri Lanka. \\ Email: chathurar@uom.lk \\ * Corresponding author
}

2. Wolfson School Mechanical, Electrical and Manufacturing Engineering, Loughborough University, Loughborough, Leicestershire, LE11 3TU, UK

Email: W.Malalasekera@lboro.ac.uk 


\section{MODELLING COMBUSTION IN SPARK IGNITION ENGINES WITH SPECIAL EMPHASIS ON NEAR WALL FLAME QUENCHING}

\section{ABSTRACT}

A flame front is quenched when approaching a cold wall due to excessive heat loss. Accurate computation of combustion rate in such situations requires accounting for near wall flame quenching. Combustion models, developed without considering wall effects, cannot be used for wall bounded combustion modelling, as it leads to wall flame acceleration problem.

In this work, a new model was developed to estimate the near wall combustion rate, accommodating quenching effects. The developed correlation was then applied to predict the combustion in two spark ignition engines in combination with the famous Bray-Moss-Libby (BML) combustion model. BML model normally fails when applied to wall bounded combustion due to flame wall acceleration. Results show that the proposed quenching correlation has significantly improved the performance of BML model in wall bounded combustion.

As a second step, in order to further enhance the performance, the BML model was modified with the use of Kolmogorov-Petrovski-Piskunov analysis and fractal theory. In which, a new dynamic formulation is proposed to evaluate the mean flame wrinkling scale, there by accounting for spatial inhomogeneity of turbulence. Results indicate that the combination of the quenching correlation and the modified BML model has been successful in eliminating wall flame acceleration problem, while accurately predicting in-cylinder pressure rise, mass burn rates and heat release rates.

\section{Keywords}

SI engine combustion; flame quenching; wall flame acceleration; BML model. 


\section{INTRODUCTION}

Internal combustion engines (IC) operating on fossil fuels provide $25 \%$ of the total energy demand of the word [1] and are expected to dwell few more decades [2]. The greatest challenge of IC engine development will be to meet stringent emission targets while achieving increased efficiency. Understanding the combustion process in IC engines is always demanding. It is largely influenced by turbulent in-cylinder flow. Low and moderate turbulence wrinkle the flame front, increasing the burning rate. Very high turbulence could tear apart flame fronts possibly extinguishing the flame. The presence of surrounding solid walls of the combustion chamber makes the situation further complex. A flame front is quenched when approaching a cold wall due to excessive heat loss. It is believed that the unburned hydrocarbon formation in engines is largely associated with wall quenching, owing to partial burning of fuels.

Understanding wall flame quenching phenomenon has been a decades long research problem. One of the early studies of Daniel [3] provides imaging evidence of near wall flame quenching in IC engines. Subsequently, numerous experimental work has been reported $[4,5]$. Recent work in [6-9] provide an insight into the progress of numerical modelling of flame-wall interaction in IC engines. In addition, quenching of laminar and turbulent flames in various other configurations have been studies in [10-18].

Despite the significance of wall flame quenching, there is only limited work reported on its numerical modelling. Often, the near wall interactions have been neglected, which in turn resulted in flame wall acceleration problem in models such as BML, Eddy Break-Up and Coherent Flamelet [6, 19-21]. In order to tackle this issue, several techniques have been used. Nishiwaki [22] substituted near wall region with incombustible fuel, while Watkins et al. [20], Abu-Orf \& Cant [21] used emeprical scaling functions. Poinsot et al. [6] introduced a wall function approach and Jennigs [23] modified the near wall laminar burning velocity. Theoretically sound comprehensive 
models considering near wall turbulence as well as the thermal quenching have been developed by Bruneaux et al. [10] and Suckart \& Linse [15]. Recent direct numerical simulations on near wall flame interactions reported in $[8,14,24]$ are also notable in understanding near wall scalar transport.

The work presented here is in two parts. First it proposes a new correlation for the computation of near wall combustion rate affected by thermal quenching, based on experimental measurements of Foucher et al. [4]. The correlation can be used in conjunction with a turbulence combustion model to compute the species consumption rate of a reacting mixture closer to a cold wall. This correlation was used together with the classical BML model, which is inherently not suitable for modelling near wall combustion. Secondly, the BML model was further improved using KPP analysis and fractal theory to eliminate some of the deficiencies of the original BML model. The developed quenching correlation in the first part was then tested with the improved BML model. Both model formulations were applied to predict the wall bounded combustion in two spark ignition (SI) engines.

\section{MODELLING NEAR WALL QUENCHING RATE}

The rate of quenching depends on the relative intensity of heat release from combustion and the heat loss to the cold boundary. There exist two distinct quenching regions as illustrated in Figure 1. The region adjacent to the wall is termed "total quenching region". No combustion takes place in this region. Estimated thickness of this region corresponds to a Peclet number $(P e)$ of 3.5 [6]. This could be even high as 7.0 in engine conditions [25]. Peclet number is the ratio between flame power and wall heat flux, which simplifies to;

$$
P e=y / \delta_{L}
$$


where $y$ is the distance from wall and $\delta_{L}$ is a characteristic flame thickness given by $\delta_{L}=\Gamma / S_{L}^{0}$ under unity Lewis number. Here, $\Gamma$ is the mass diffusivity and $S_{L}^{0}$ is the unstretched laminar flame speed. The region, above the total quenching zone is called partial quenching or influenced zone. Flame front is influenced by the presence of the solid wall and is partially quenched in this region. Peclet number corresponding to the thickness of the influenced zone is about 10.

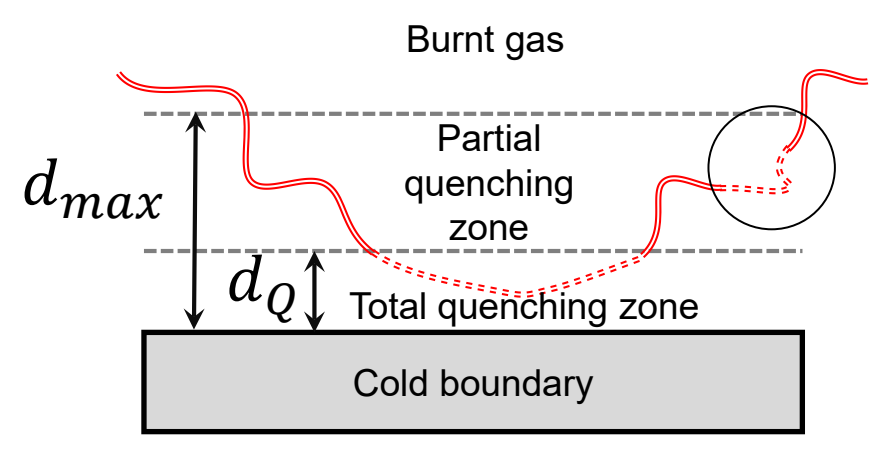

(a)

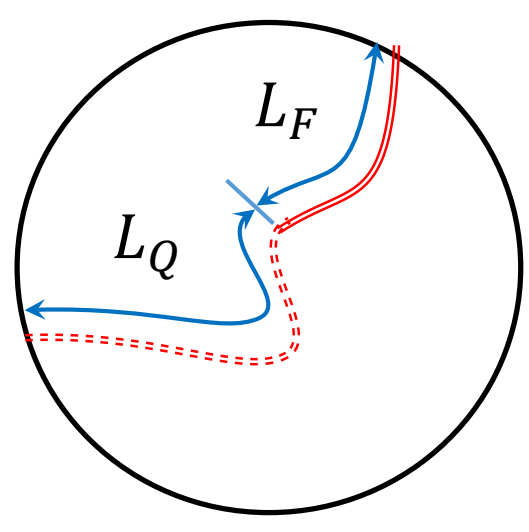

(b)

Figure 1: (a) Two zones in flame wall quenching: Total and partial quenching zones

(b) Active and quenched flame fronts within the area indicated by a circle in (a) - zoomed view.

Experimental work of Foucher et al. [4] broaden the understanding of quenching phenomenon in engines. Laser tomographic images of head-on quenching of methane-air flames in an optical engine revealed that the influenced zone could be as thick as 40 times the quenching zone. Using fractal theory Foucher \& Rousselle [5] evaluated the active flame surface area in the influenced zone and introduced the quenching rate parameter $I_{Q R}$, which can be used in estimating near wall combustion rate in the following manner.

$$
\omega_{w}=\rho_{u} I_{0} S_{L}^{0} \Sigma \times I_{Q R}
$$


where, $\omega_{w}$ is the near wall unburned gas consumption rate per unit volume and $\rho_{u}$ is the unburned gas density. $\Sigma$ is the flame surface density (FSD). Strain effects on the flame propagation speed is introduced by the stretch factor $I_{0}$.

$I_{Q R}$ is the ratio between the length of the active flame $\left(L_{F}\right)$ to the total flame length $\left(L_{F}+L_{Q}\right)$, which are estimated via fractal theory (see Figure $1(\mathrm{~b})$ ). $L_{Q}$ is the quenched length of a flamelet segment. Even though $I_{Q R}$ is named as "quenching rate parameter" in [5], it is directly proportional to the active flame area. However, for consistency, the same terminology is used here as well. Note that, $I_{Q R}$ is zero inside the total quenching region, while $0<I_{Q R}<1$ in the partial quenching zone. Figure 2 (a) shows the experimentally evaluated $I_{Q R}$ values by Foucher \& Rousselle [5] for the head-on quenching in the optical engine. Here, for all equivalence ratios $(\phi)$ considered, $I_{Q R}$ seem to vary linearly closer to the wall and then, decay exponentially towards unity at the outer boundary of the influenced zone.
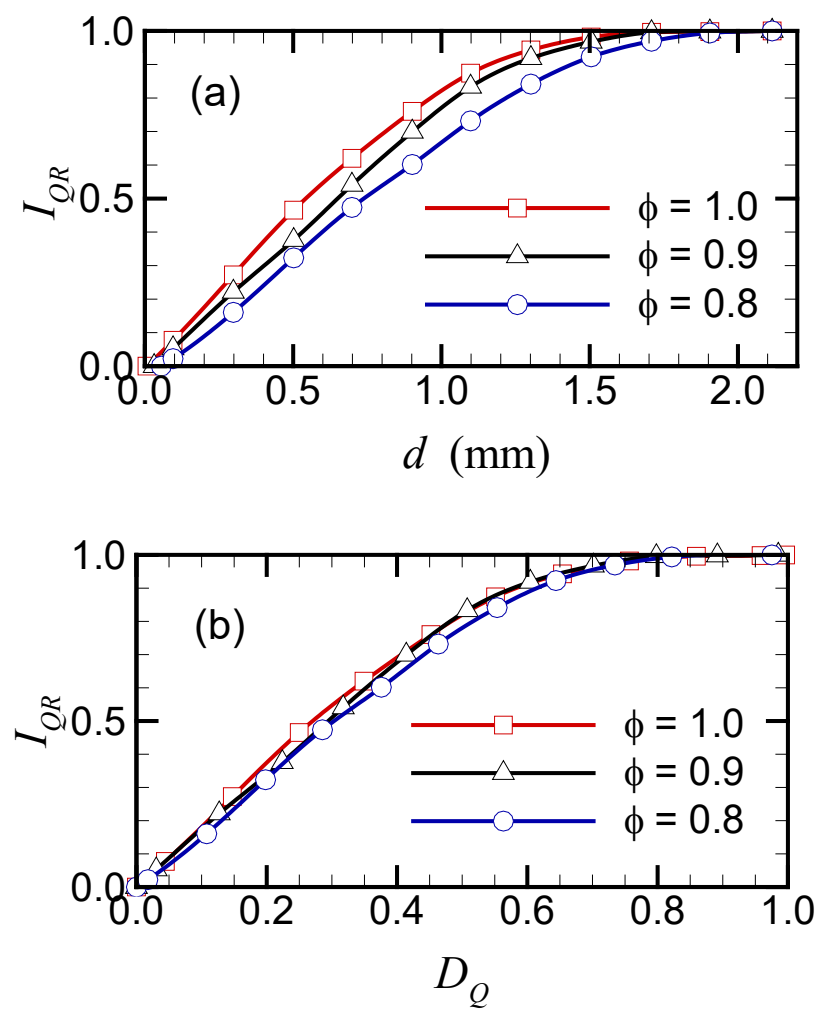
Figure 2: (a) Quenching rate vs. the distance from wall - Experimentally estimated by Foucher \& Rousselle [5].

(b) Quenching rate vs. normalized distance from the wall

Estimation of $I_{Q R}$ by Foucher \& Rousselle [5] was limited to an experimental analysis and no mathematical correlation presented. The work presented here extends their work by formulating such a correlation so that their findings could be effectively implemented in a numerical computation. The following section briefly explains the development of these correlations.

\subsection{QUENCHING RATE CORRELATION}

The non-dimensional normalized distance $D_{Q}$ is defined as:

$$
D_{Q}=\frac{d-d_{Q}}{d_{\max }-d_{Q}}
$$

where $d\left(d_{Q}<d<d_{\text {max }}\right)$ is the wall normal distance (see Figure $\left.1(\mathrm{a})\right), d_{Q}$ is the thickness of the total quenching zone and $d_{\max }$ is the distance to the outer boundary of the influenced zone. Shown in Figure 2 (b) is the variation of $I_{Q R}$ with respect to $D_{Q}$ for data in [5]. Variation of $I_{Q R}$ with $D_{Q}$ also shown to be linear closer to the wall and exponentially decay towards unity at the outer boundary of the influenced zone. It was observed during the present work that $I_{Q R}$ can be related to $D_{Q}$ by the following curve fitted expression.

$$
I_{Q R}=1.0-\frac{2.0}{1+\exp \left(D_{Q}\right)^{\alpha}}
$$

Exponent $\alpha$ is introduced as the rate of decay of $I_{Q R}$ increases with the increasing wall normal distance.

$$
\alpha=\frac{\beta}{\left(1.0-0.6 D_{Q}\right)}
$$

The effect of $\phi$ on $I_{Q R}$, is embedded via parameter $\beta$ given by 


$$
\beta=3.7-2|\phi-1.0|
$$

Other numerical values were obtained by calibrating the model to the experimental data. Equation for $\beta$ assumes that minimum rate of quenching occurs at $\phi=1$. For many types of fuels, this is a quite valid assumption, as the quenching Peclet number is symmetric about $\phi=1$ or has only a little offset [26]. Figure 3 depicts the comparison of $I_{Q R}$ values estimated using expressions in Eq. (4) - (6), with experimental data in [5]. These figures show that the computed values are in very good agreement for the entire quenching region.
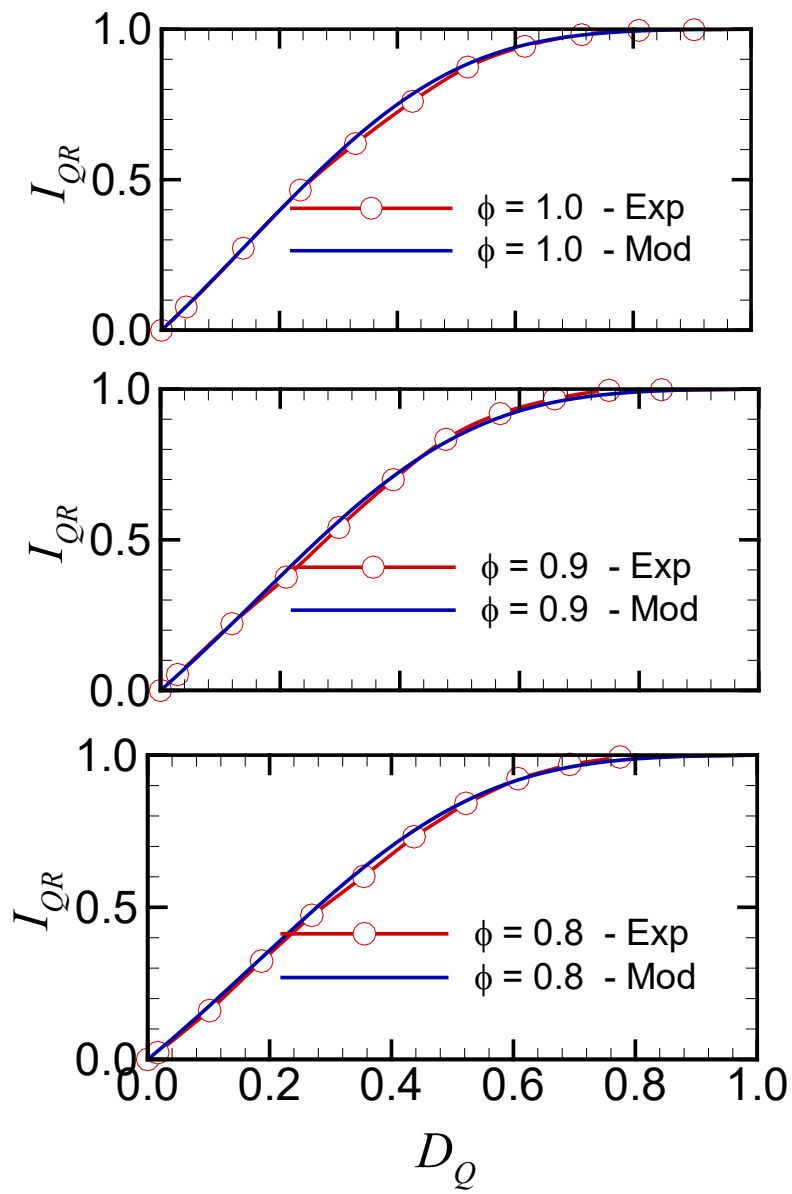

Figure. 3. Variation of quenching rate for $\phi=1.0,0.9 \& 0.8$ 
It is customarily to represent the parameters related to quenching, in terms of the Peclet number. Hence, normalizing $d$ with respect to $\delta_{L}$ leads $D_{Q}$ to be recast as

$$
D_{Q}=\frac{d-d_{Q}}{d_{\max }-d_{Q}}=\frac{\left[d / \delta_{L}-d_{Q} / \delta_{L}\right]}{\left[d_{\max } / \delta_{L}-d_{Q} / \delta_{L}\right]}=\frac{P e-P e_{Q}}{P e_{\max }-P e_{Q}}
$$

Once a suitable relation for $P e_{Q}$ and $P e_{\text {max }}$ is given, Eq. (4)-(7) can effectively be used in modelling studies to account for the reduction in burning rate near solid walls. Following, Suckart et al. [25] assuming equal diffusivities of all chemical species, the characteristic flame thickness $\delta_{L}$ was taken to be the diffusive flame thickness given by Eq (8), where $v$ is the kinematic viscosity of unburned gas.

$$
\delta_{L}=v / S_{L}^{0}
$$

Effect of heat loss on the flame thickness was not explicitly considered, yet limited to the influence of temperature on the local values of $v$ and $S_{L}^{0}$.

In general for piston engines, $P e_{Q}$ is around $3.5-4.0$ for stoichiometric air-fuel mixtures $[6,25]$. It largely depends on $\phi$, while weakly depends on pressure $(P)$, fuel type and temperature. Despite considerable work, there is no any comprehensive formulation to evaluate $P e_{Q}$ considering all influential parameters. Analysis of experimental quenching distances for many fuels has lead Lavoie [26] to suggest that,

$$
P e_{Q}=\frac{1.9}{\phi}\left(\frac{P}{3}\right)^{0.26 \min \left(1,1 / \phi^{2}\right)}
$$

This expression contains the effects of $\phi$ and $P$, but not the temperature. Westbrook [27] proposed $d_{Q}=68 . P^{-0.44}$ and Labuda [28] proposed $d_{Q}=88 . P^{-0.48}$ considering only the pressure 
dependency. Consequntly Eq(9) was used in this work to determine $P e_{Q}$. The maximum Peclect number was taken to be 40 , based on the experimental evidence of Foucher \& Rousselle [5].

\section{THE BML COMBUSTION MODEL}

In order to illustrate the effectiveness of the proposed quenching rate formulation in SI engines, the model was incorporated to the Bray Moss Libby combustion model. The BML model was chosen for this work due to few reasons. The BML model [26] has been originally developed for predicting combustion in core regions of flames where no wall effects present. Hence, applied to wall bounded systems, it produces extremely high reaction rates near walls leading to wall flame acceleration. Consequently, it has become impossible to use these models without modifying for SI engine simulations (see [20]). Therefore, any improvement due to the present modifications by introducing wall-flame interactions, shall be clearly detected from predicted results by integrating with the BML model.

During combustion, the unburned mass consumption rate per unit volume $\overline{\dot{\omega}}$, can be given by:

$$
\overline{\dot{\omega}}=\rho_{u} I_{0} S_{L}^{0} \Sigma
$$

Turbulent and curvature strain effects on the flame propagation speed is modelled by $I_{0}$ (see [30]). In the present work, $I_{0}$ was estimated following Law et al. [31]. $S_{L}^{0}$ was calculated from Gülder's [32] correlation for Octane. $\Sigma$ represents the available mean flame surface area per unit volume. In the BML model FSD is given by

$$
\Sigma=\frac{g}{\left|\sigma_{y}\right|} \frac{\bar{c}(1-\bar{c})}{L_{y}}
$$


where $\bar{c}$ is the mean progress variable of reaction. $L_{y}$ is the integral scale of flame wrinkling and $g$ is a model constant with value ranging from 0.5 to 2 [33]. Bray [34] correlated $L_{y}$ to the integral scale of turbulence $L_{i}$ as:

$$
L_{y}=C_{b} L_{i}\left(\frac{S_{L}^{0}}{u^{\prime}}\right)^{n}
$$

where $C_{b}=1$ and $n$ are model constants with,

$$
L_{i}=C_{L} u^{\prime 3} / \varepsilon
$$

$C_{L} \sim 0.4$ [35] is a model constant, $u^{\prime}$ is the turbulence intensity and $\varepsilon$ is the rate of dissipation of turbulence kinetic energy. As Favre averaged equations are solved in combustion studies, it is convenient to replace the mean progress variable with the Fevre averaged progress variable $\tilde{c}$, so that $\Sigma$ can be written as:

$$
\begin{gathered}
\Sigma=\frac{g}{\left|\sigma_{y}\right|} \frac{1+\tau}{(1+\tau \tilde{c})^{2}} \frac{\tilde{c}(1-\tilde{c})}{L_{y}} \\
\bar{c}=\frac{(1+\tau) \tilde{c}}{1+\tau \tilde{c}} \\
\tau=\frac{\tilde{\rho}_{u}}{\tilde{\rho}_{b}}-1
\end{gathered}
$$

The heat release factor $\tau$ is defined using Fevere averaged fresh $\left(\tilde{\rho}_{u}\right)$ and burned gas $\left(\tilde{\rho}_{b}\right)$ densities. Combining Eq (11) through (16) the reaction term of the BML model can be recast as: 


$$
\overline{\dot{\omega}}=\rho_{u} I_{0} S_{L}^{0} \frac{g}{\left|\sigma_{y}\right|} \frac{1+\tau}{(1+\tau \tilde{c})^{2}} \frac{\tilde{c}(1-\tilde{c})}{L_{i}\left(\frac{S_{L}^{0}}{u^{\prime}}\right)^{n}}
$$

\subsection{A MODIFIED BML MODEL}

As it was noted earlier, the BML model has some inherent problems. It assumes isotropic homogeneous turbulence. Near solid boundaries, the BML model fails owing to the inhomogeneous nature of turbulence, as $u^{\prime}$ rapidly decays towards the wall. Thus in the BML formulation, $L_{i} \sim u^{\prime 3} / \varepsilon$ and $L_{y}$ tend to be small near walls, making $\Sigma$ un-physically large. To resolve this issue, an alternative formulation for $L_{y}$ is suggested here based on the Kolmogorov - Pertovsky - Piskunow (KPP) analysis and fractal modelling of combustion. The new model accounts for the variations of $L_{y}$ resulting from inhomogeneity of turbulence. Derivation of this model is detailed below.

\subsubsection{KPP ANALYSIS OF THE BML MODEL}

KPP analysis can be used to compare different combustion models in terms of equivalent turbulent burning velocity computed by each model, under frozen turbulence assumption. Poinsot \& Veynante [36] provides a detailed description on the KPP analysis. At the leading edge of the flame, when $\tilde{c}$ goes to zero, neglecting higher order terms of $\tilde{c}$, the reaction term in $\mathrm{Eq}(17)$, can be rearranged to obtain the following.

$$
\overline{\dot{\omega}}_{0}=\rho_{u} I_{0} S_{L}^{0} \frac{g}{\left|\sigma_{y}\right|} \frac{1+\tau}{L_{i}\left(\frac{S_{L}^{0}}{u^{\prime}}\right)^{n}} \tilde{c}
$$


Where $\bar{\omega}_{0}$ is the reaction rate at the leading edge of the flame. According to the KPP theorem, equivalent turbulent speed of the BML model is

$$
S_{T, B M L}=\sqrt{4 D_{t} I_{0} S_{L}^{0} \frac{g}{\left|\sigma_{y}\right|} \frac{1+\tau}{L_{i}\left(\frac{S_{L}^{0}}{u^{\prime}}\right)^{n}}}
$$

Bray [33] proposed that the turbulent diffusely term can be expressed by $D_{T} \sim C_{e} u^{\prime} L_{i}$, so that,

$$
S_{T, B M L}=\sqrt{4 C_{e} u^{\prime} I_{0} S_{L}^{0} \frac{g}{\left|\sigma_{y}\right|} \frac{1+\tau}{\left(\frac{S_{L}^{0}}{u^{\prime}}\right)^{n}}}
$$

where, $C_{e}$ is a model constant.

On the other hand, using fractal theories [34], the ratio between turbulent and strained laminar flame speeds $S_{L}$ can be correlated by:

$$
\frac{S_{T}}{S_{L}}=C_{t}\left(\frac{\epsilon_{0}}{\epsilon_{i}}\right)^{D-2}
$$

where, $\epsilon_{i}$ and $\epsilon_{o}$ are inner and outer cut off length scales of flame wrinkling. The fractal dimension $D$ indicates of how wrinkled the surface. $D$ is equally influenced by all the turbulence scales. The parameter $C_{t}$ is a function of the turbulence field, though assumed constant in some studies. Gülder \& Smallwood [38] recognized that this would result in modelling deficiencies and suggested that $C_{t} \sim\left(u^{\prime} / S_{L}\right)^{1 / 2}$. Thus, equating the turbulent velocities of both models given by Eq. (20) and Eq. (21) yields: 


$$
S_{T}=\left(\frac{u^{\prime}}{S_{L}^{0}}\right)^{1 / 2} I_{0}{ }^{1 / 2} S_{L}^{0}\left(\frac{\epsilon_{0}}{\epsilon_{i}}\right)^{D-2}=S_{T, B M L}=\sqrt{4 C_{e} u^{\prime} I_{0} S_{L}^{0} \frac{g}{\left|\sigma_{y}\right|} \frac{1+\tau}{\left(\frac{S_{L}^{0}}{u^{\prime}}\right)^{n}}}
$$

If the outer and inner cut off scales of flame wrinkling is taken to be the Gibson scale $\left(L_{G} \sim S_{L}^{0^{3}} / \varepsilon\right)$ [39] and the integral scale $\left(L_{i} \sim u^{\prime 3} / \varepsilon\right)$ respectively, the wrinkling ratio of the fractal model becomes,

$$
\left(\frac{\epsilon_{0}}{\epsilon_{i}}\right)^{D-2} \sim\left(\frac{u^{\prime}}{S_{L}^{0}}\right)^{3(D-2)}
$$

Substituting Eq. (23) in Eq. (22) and considering only dimensional terms,

$$
\left(\frac{u^{\prime}}{S_{L}^{0}}\right)^{1 / 2} \frac{u^{\prime 3(D-2)}}{S_{L}^{0^{(3 D-7)}}} \sim \sqrt{\left(\frac{u^{\prime n+1}}{S_{L}^{0^{n-1}}}\right)}
$$

As both sides of the equation are dimensionally the same, it is understood that:

$$
n=6 D-12
$$

Consequently, using this expression for $n$, the complete model form of the modified BML model, including the quenching rate parameter $I_{Q R}$ can be recast as follows:

$$
\overline{\dot{\omega}}=I_{Q R} \rho_{u} I_{0} S_{L}^{0} \frac{g}{\left|\sigma_{y}\right|} \frac{1+\tau}{(1+\tau \tilde{c})^{2}} \frac{\tilde{c}(1-\tilde{c})}{C_{L} \frac{u^{\prime 3}}{\varepsilon}\left(\frac{S_{L}^{0}}{u^{\prime}}\right)^{6 D-12}}
$$

The fractal dimension varies both spatially and temporally during the engine cycle. North \& Santavicca [40] suggested that $D$ can be modelled as Eq (27) as the rate of wrinkling and smoothing is proportional to $u^{\prime}$ and $S_{L}^{0}$ respectively. This formulation limits the maximum possible $D$ value close to 2.35 and hence, the maximum attainable $n$ value would be about 2.1. 


$$
D=\frac{2.05 S_{L}^{0}+2.35 u^{\prime}}{u^{\prime}+S_{L}^{0}}
$$

During the present work, both BML model forms combined with the developed quenching rate model were implemented to the engine CFD code and evaluated. In order to distinguish different model forms, the standard BML model with constant $n=1$ was named as $\mathrm{M} 1$ and modified BML model given by Eq (26) with $I_{Q R}=1$, neglecting wall quenching effects was taken as M2. Eq (26) with the $I_{Q R}$ calculated using above quenching model was taken as M3.

\section{VALIDATION OF THE COMBUSTION MODELS}

The aim here is to benchmark the developed combustion models, using published literature. Accordingly, the combustion in propane fuelled, flat head-flat piston GM engine with a centrally located spark plug, reported by Kuo and Reitz [41] was simulated. Specifications and geometric details of the engine are given in Table 1.

Table 1: Engine Specifications

\begin{tabular}{|c|c|c|c|c|}
\hline Bore $(\mathrm{cm})$ & \multirow{7}{*}{ 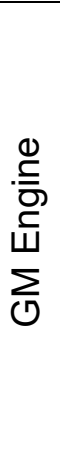 } & 10.50 & \multirow{7}{*}{ 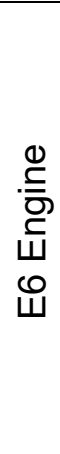 } & 7.62 \\
\hline Stroke $(\mathrm{cm})$ & & 9.525 & & 11.11 \\
\hline $\begin{array}{l}\text { Connecting rod length } \\
(\mathrm{cm})\end{array}$ & & 15.80 & & 24.13 \\
\hline $\begin{array}{l}\text { Intake valve opening } \\
\text { (IVO) }\end{array}$ & & $30^{\circ} \mathrm{BTDC}$ & & $9^{0} \mathrm{BTDC}$ \\
\hline Intake valve closing (IVC) & & $243^{\circ}$ ATDC & & $217^{0}$ ATDC \\
\hline Compression ratio & & 8.56 & & Variable \\
\hline Fuel & & Propane & & Gasoline \\
\hline
\end{tabular}

\subsection{NUMERICAL SETUP AND TEST CONDITIONS}

All computations reported here were conducted using the KIVA-4 engine code [42]. Favre Averaged Naiver - Stokes equations were solved using an arbitrary Lagrangian Eulerian method. Turbulence was modelled using the $k-\varepsilon$ model and near wall flow was treated using standard 
wall functions. Discrete particle ignition kernel (DPIK) proposed by Fan \& Reitz [43] and subsequently improved in [44] and [45] was used for modelling ignition and early flame development. Simple oxidisation of fuel was considered and fully developed phase of combustion was computed using the developed combustion models as explained above. Subsequent products are taken to be in equilibrium following the reactions described in [46].

Calculations of the GM engine started at IVC during compression. Engine mesh comprise of 320,000 unstructured hexahedral cells from which 100,000 cells are in the squish region making the average squish cell size $1 \mathrm{~mm}$. The mesh configuration is quite similar to that of the $\mathrm{E} 6$ engine mesh shown in the Figure 7, yet without ports. Operating conditions chosen to investigate the model behaviour in changing equivalence ratio, engine speed, spark advance and loads are summarized in Table 2.

Table 2: $\quad$ Operating conditions of the GM engine

\begin{tabular}{lccccccccc}
\hline \hline $\begin{array}{l}\text { Case } \\
\text { No }\end{array}$ & $\phi$ & RPM & $\begin{array}{l}\text { Spark } \\
(\mathrm{BTDC})\end{array}$ & $\begin{array}{c}\text { Wall } \\
\text { temp } \\
(K)\end{array}$ & $\begin{array}{c}\text { Temp } \\
\text { IVC } \\
(K)\end{array}$ & $\begin{array}{c}u_{I V C}^{\prime} \\
(\mathrm{cm} / \mathrm{s})\end{array}$ & $\begin{array}{c}L_{i} \\
\text { IVC } \\
(\mathrm{cm})\end{array}$ & $\begin{array}{l}\text { Residual } \\
\text { mass } \\
(\%)\end{array}$ & $\begin{array}{l}\text { Trapped } \\
\text { mass } \\
(\mathrm{g})\end{array}$ \\
\hline 1 & 0.87 & 1500 & $27^{0}$ & 420 & 453 & 46 & 0.403 & 12.0 & 0.486 \\
2 & 0.87 & 1500 & $27^{0}$ & 440 & 429 & 46 & 0.403 & 9.8 & 0.710 \\
3 & 0.98 & 1500 & $27^{0}$ & 425 & 453 & 46 & 0.403 & 14.0 & 0.499 \\
4 & 0.87 & 1000 & $29^{\circ}$ & 405 & 436 & 31 & 0.403 & 13.8 & 0.496 \\
\hline \hline
\end{tabular}

In order to assess the effectiveness of wall flame quenching correlation in elimination wall flame acceleration problem, the near wall flame behaviour during the combustion in GM engine was examined. Depicted in the Figure 4 is the reaction progress variable on an axial plane for different crank positions. Region with $0<\tilde{c}<1$ shows the reaction zone. The wall flame acceleration problem associated with the BML model is clearly evident from column M1. Flame is shown to propagate rapidly along the cylinder head surface at the early stage $\left(-15^{0}\right.$ and $\left.-10^{\circ}\right)$, and then 
along the piston surface $\left(-5^{0}\right.$ and $\left.0^{0}\right)$. In both these regions, $\tilde{c}$ becomes unity on walls much faster than the core area, attesting the problematic nature. As a result, the flame front is shown to be concave shaped, where it is convex in practise.

Predictions of model form M2, are shown in column M2. Use of dynamic fractal formulation for evaluating flame wrinkling scale has made a substantial improvement over $\mathrm{M} 1$, and the flame front also appears to be convex. However, a relatively a higher near wall reaction rate can still be observed (see $\left.-10^{\circ}\right)$, as no wall flame quenching effect is considered.

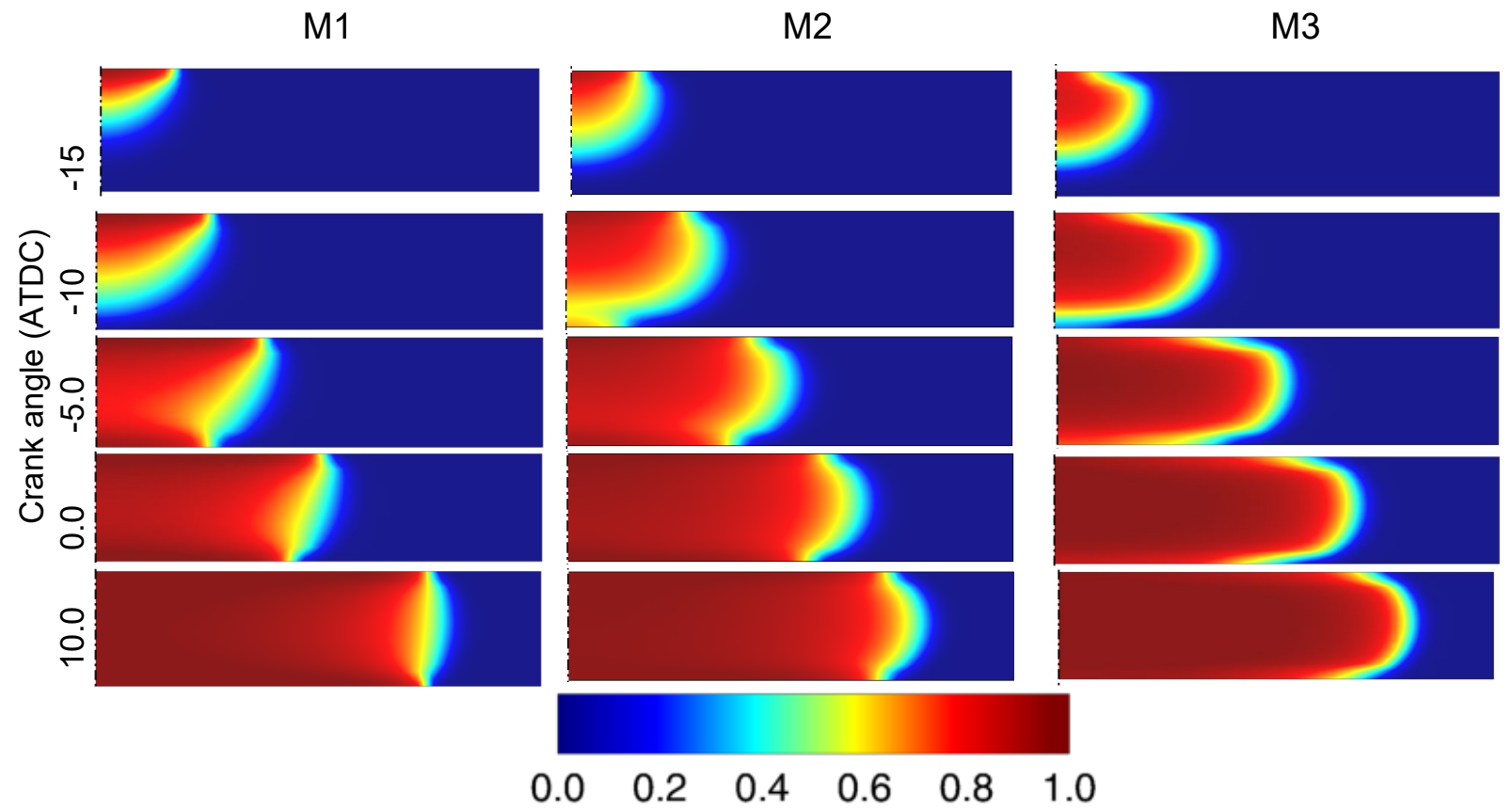

Figure 4: Flame propagation represented by the reaction progress variable for GM engine. Top edge of each figure indicates the cylinder head, while the bottom indicates the piston surface. Spark plug is centrally located. Only one half of the section plane shown.

M3 column shows the combined effect of $\mathrm{M} 2$ and quenching parameter $I_{Q R}$. Accordingly, a marked reduction of near wall reaction rate is shown, completely eliminating the wall flame acceleration. The flame brush is also shown to be thinner than the other model forms while the 
flame front is also agreeably convex. These observations are well in agreement with optical engine studies such as [19].

Estimation of in cylinder pressure and fuel burning rate is crucial in engine combustion modelling. Hence, the pressure and burned fuel mass fraction predictions by model form $M 1, M 2$ and $M 3$, are compared with the experimental measurements as shown in Fig. 5 and 6 . Note that predictions of M1 and M2 are shown only to highlight the relative effects of each modifications suggested in this work. The discussion below is limited to the performance of M3 model which is the final model form proposed. In general, the results of M3 model are in good agreement for all cases and are quite encouraging. Pressure and mass burn data during the initial and middle stages of combustion have been well captured by the model, though there is a slight discrepancy in the prediction of peak pressure. Computed burned mass fractions also match very well with experiments from ignition to major part of the combustion. However, an over prediction can be observed during the early stage and the latter part of combustion. Apparently, the experimental mass burn rate derived using in cylinder pressure trace, significantly drops, after $10^{\circ}$ of TDC and could be due to the excessive wall heat loss as the flame reaches cylinder walls. The present model has not adequately grasped this phenomenon, and consequently resulting over prediction in mass burn rates at the latter stage of combustion. 

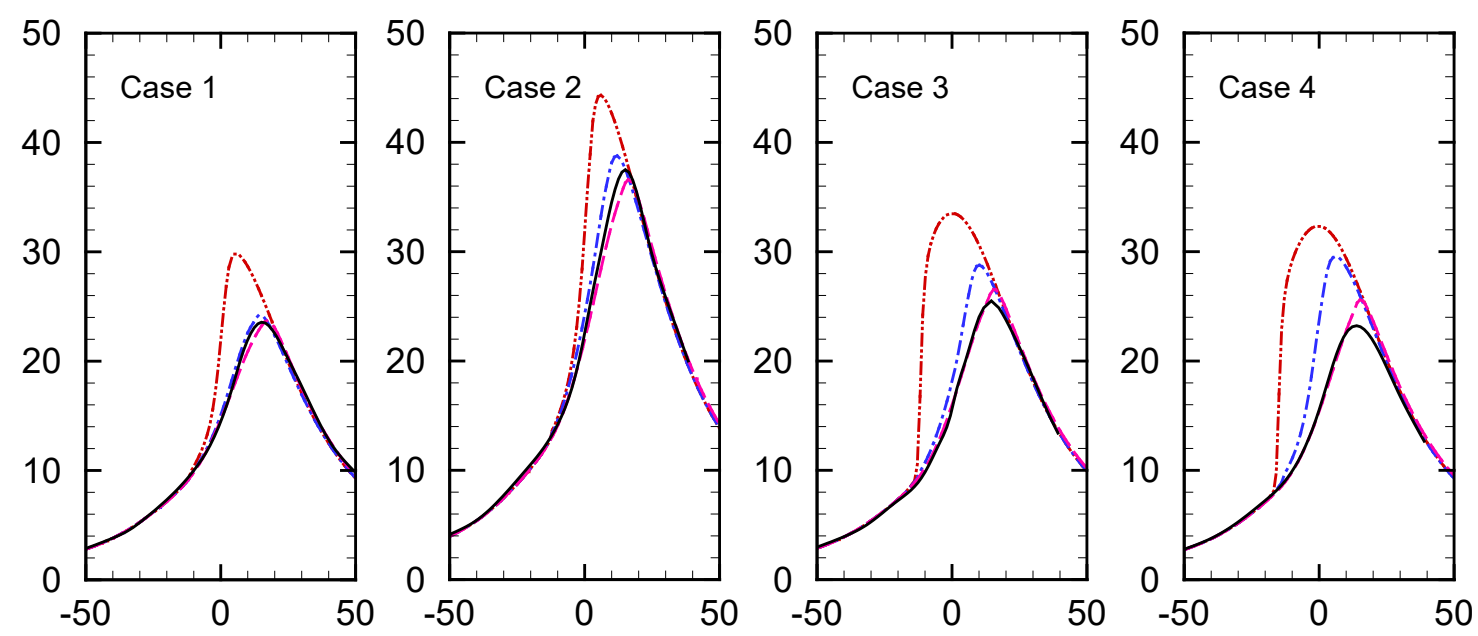

Figure 5: Comparison of cylinder pressure for GM engine. Line patterns correspond to model M1: Dash-Dot-Dot, M2: Dash-Dot, M3: Long Dash and Experimental : Solid.
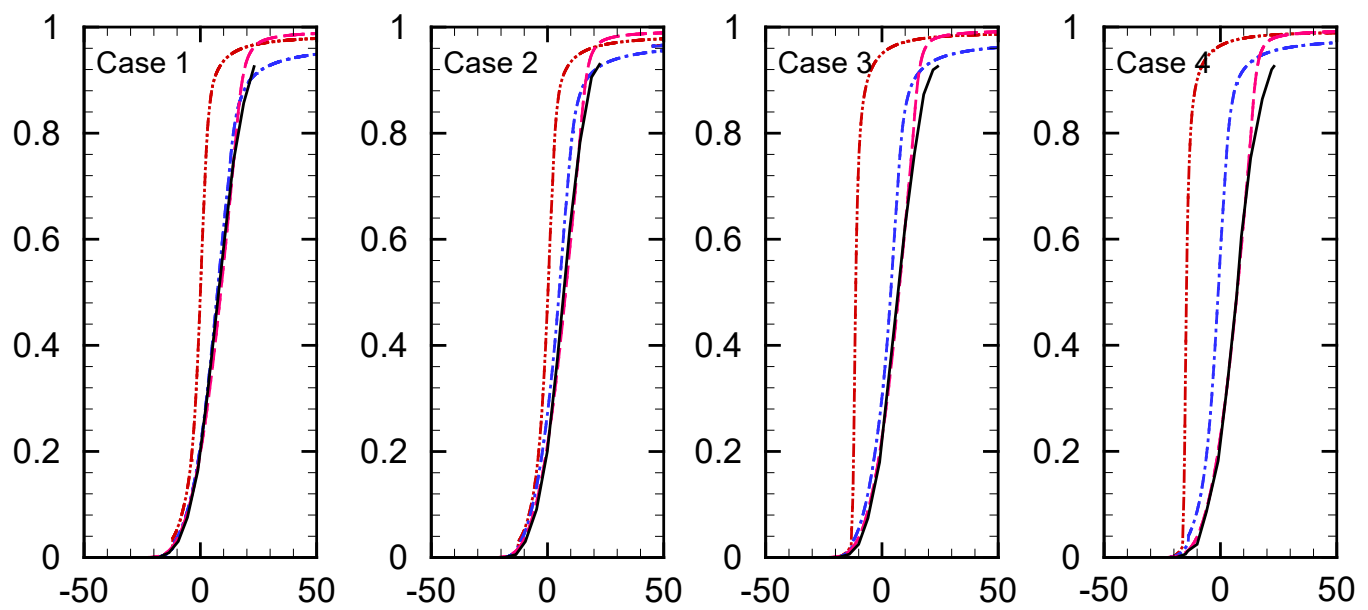

Figure 6: Comparison of predicted fuel mass fraction for GM engine. Line patterns correspond to model M1: Dash-Dot-Dot, M2: Dash-Dot, M3: Long Dash and Experimental : Solid. 


\section{FULL CYCLE SIMULATION OF THE RICARDO E6 ENGINE}

In order to further assess the ability of the M3 model form, full cycle simulations of Ricardo E6 engine were carried out. These simulations represent more realistic situation than the GM engine cases, as all four stokes including port flow are modelled. Simulating intake and port flow provides a mean to properly estimate the spatial variations of turbulence, swirl and tumble motion while full cycle simulations automatically introduce residual gases and subsequent species mixing and heat transfer effects. Major specifications of E6 engine are given in table 1.

\subsection{NUMERICAL SETUP AND TEST CONDITIONS}

With the intension of assessing M3 model response in varying operating conditions, four different test cases were selected as in Table 3. Case 1, operating under full load was taken to be the reference. In case 2 equivalence ratio is altered. Engine speed and spark timing under part load is varied in case 3 . In case 4, compression ratio is changed. The engine mesh at BDC shown in Figure 7, has about 400,000 unstructured hexahedral cells, of which, 100,000 in squish region with an average cell size around $1 \mathrm{~mm}$. Automatic time stepping with maximum limited to 0.2 crank degrees was used. Other sub models remained similar to that of GM engine, and the fuel was taken to be isooctane. Temperature of cylinder wall, head and piston top were estimate as recommended by Zhao et al. [47].

Table 3: Operating conditions of the E6 engine

\begin{tabular}{cccccc}
\hline \hline Case & $\phi$ & RPM & $\begin{array}{l}\text { Spark advance } \\
\text { (BTDC) }\end{array}$ & Comp. ratio & $\begin{array}{c}\text { Intake air } \\
\text { temp }(K)\end{array}$ \\
\hline 1 & 1.089 & 1500 & 16 & 8.7 & 298 \\
2 & 0.936 & 1500 & 16 & 8.7 & 298 \\
3 & 0.967 & 1800 & 20 & 8.7 & 300 \\
4 & 0.953 & 1500 & 16 & 7.5 & 298 \\
\hline \hline
\end{tabular}


Computation of E6 engine started $20^{\circ}$ BTDC exhaust. Initial gas mixture was taken to be fully burned at corresponding composition to $\phi$ at measured exhaust gas temperature. Pressure at intake and exhaust were assigned from measured pressure profiles

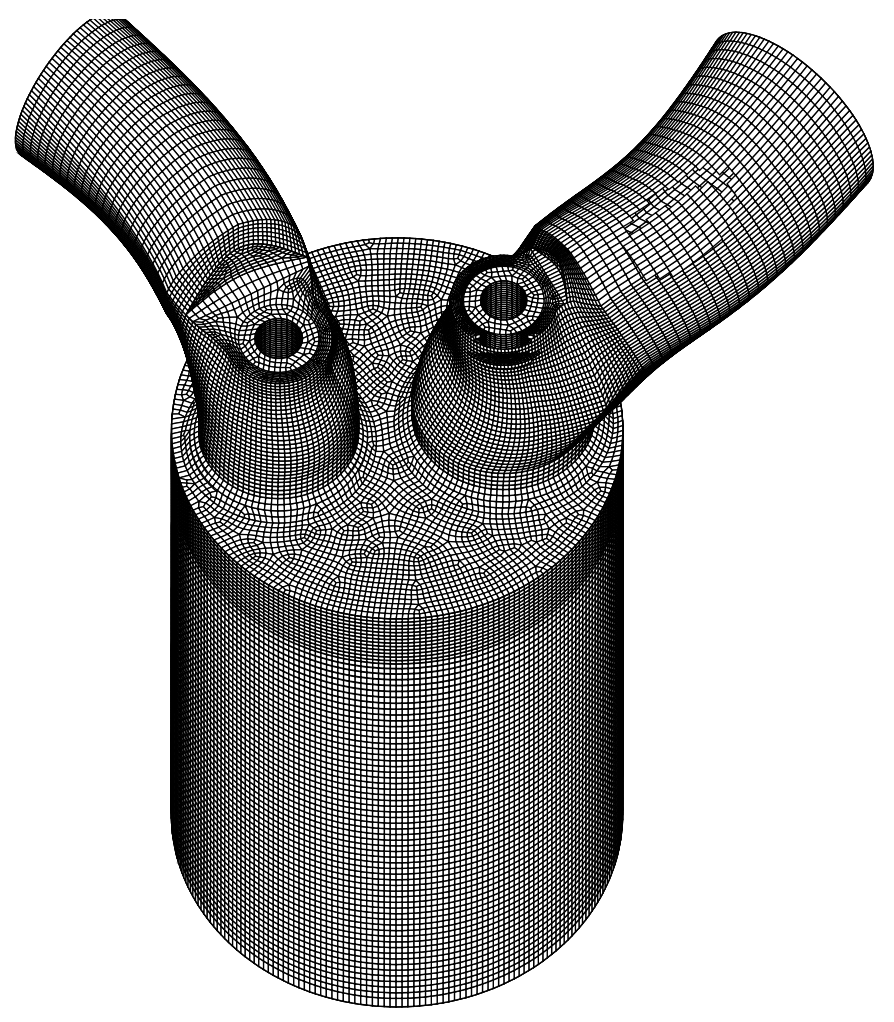

Figure 7: Computational mesh of the E6 engine. Piston at BDC

Figure 8 shows the predicted in-cylinder pressure comparison with experiments. Generally, the predicted pressure values are in good agreement with measured values. The trend in pressure variations in early, mid and latter stages of combustion, with changing operating conditions is well captured. Though, a slight over prediction is present in case 4, predicted peak pressure for all other cases are reasonably accurate. Peak pressure locations are found to be slightly shifted by 0-4 crank degrees. Further, a minor over prediction of pressure at the latter stage of power stroke 
can be seen. Case 1, which has a lower engine speed and a higher peak pressure shows a higher deviation and case 3 with higher engine speed and a slightly lower peak pressure has less deviation. As lower engine speed and higher pressures leads to higher blow by gas production, this discrepancy could be thought as a result of not having a blow by gas model in present simulations. Behaviour of the other two cases also seems to confirm this argument.
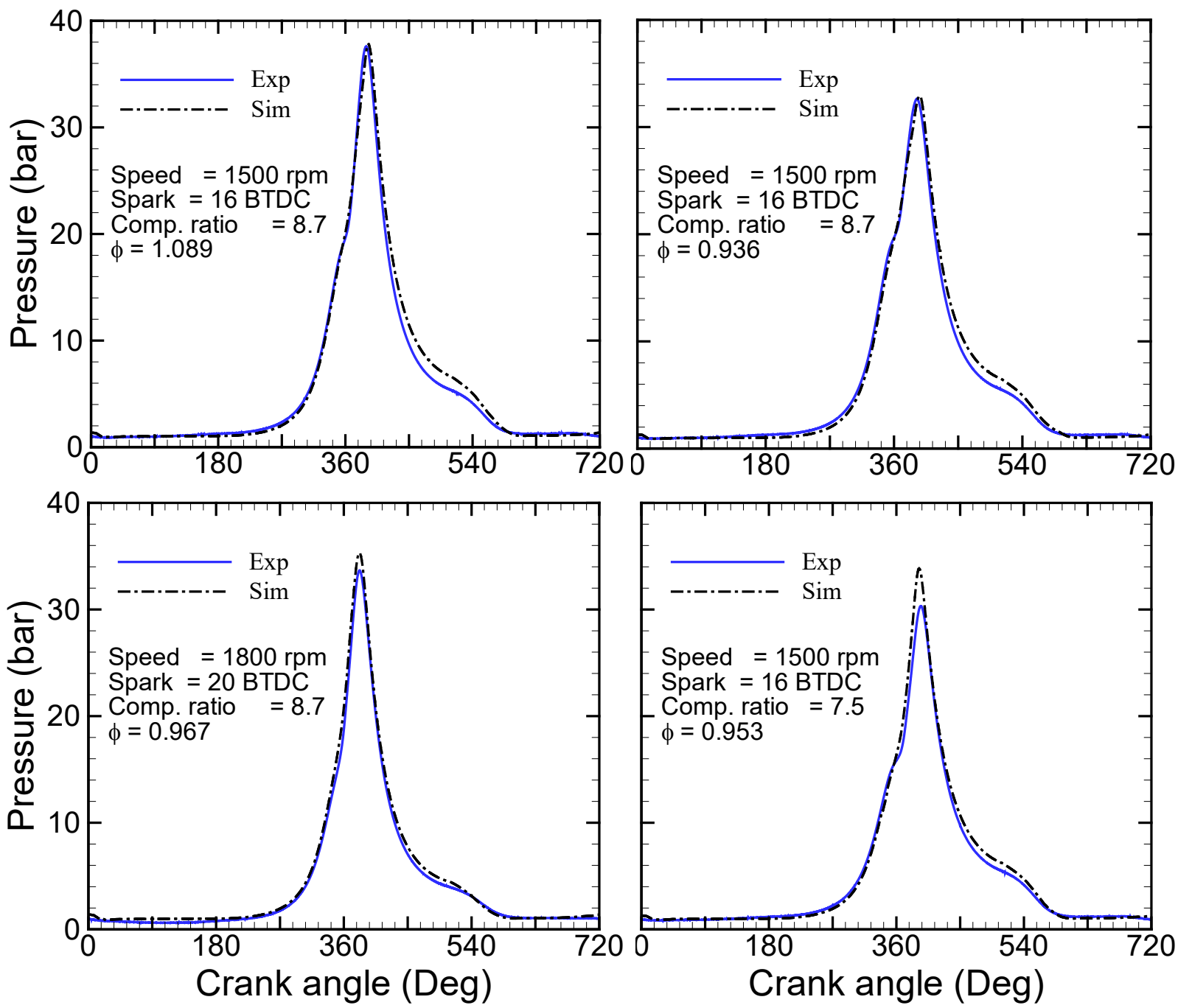

Figure 8: In-cylinder pressure of E6 engine. A comparison of predictions of M3 model vs experiments. 

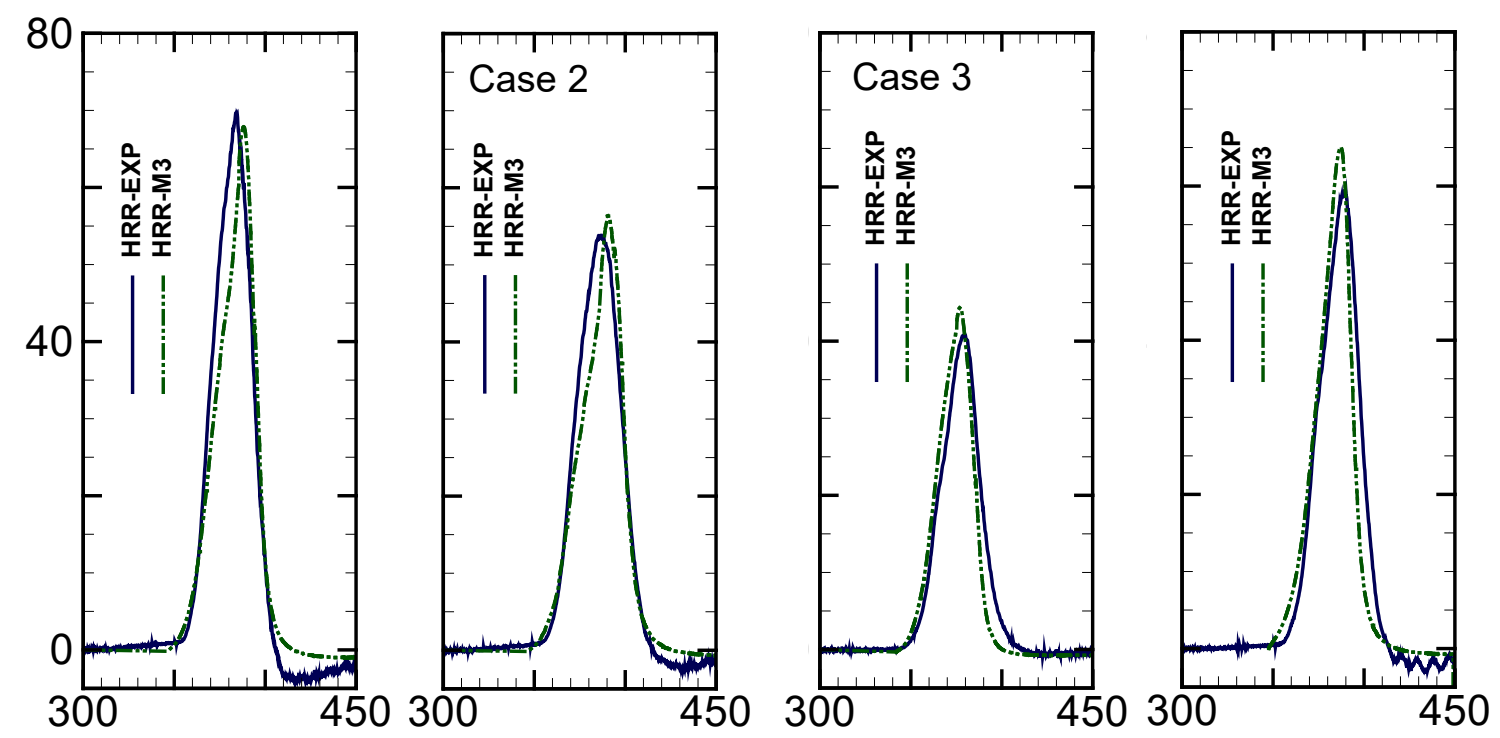

Figure 9: Instantaneous heat release rate predicted by M3 model compared with experinetal estimations
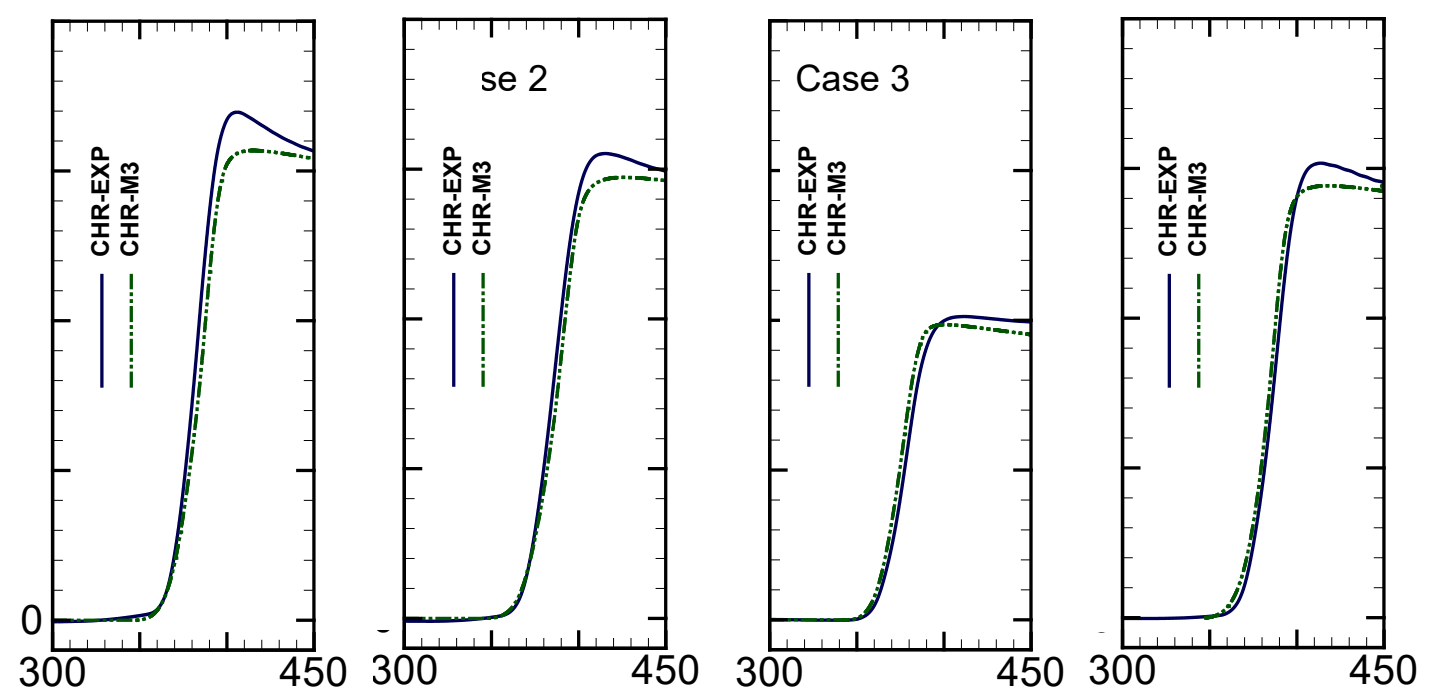

Figure 10: Cumulative heat release rate predicted by M3 model compared with experinetally estimations 
Shown in Figure 9 and 10 respectively, are the comparison of instantaneous (HRR) and cumulative $(\mathrm{CHR})$ heat release rates. Note that, these values represent the net heat release rates computed with the allowance for wall heat losses. HRR is a direct function of rate of in-cylinder pressure rise and hence, only a well formulated model could reproduce both pressure and HRR accurately. Simulated HRRs were calculated using fuel burn data and wall heat losses. Analysis of results indicate that M3 model has captured both HRR and CHRR to a satisfactory level. Predicted peak HRR are well within 10\% error margin and for case 1 and 2 it is below $5 \%$. Peak HRR location has a variation of $\pm 5^{0}$ degrees, and which is quite significant in engine applications.
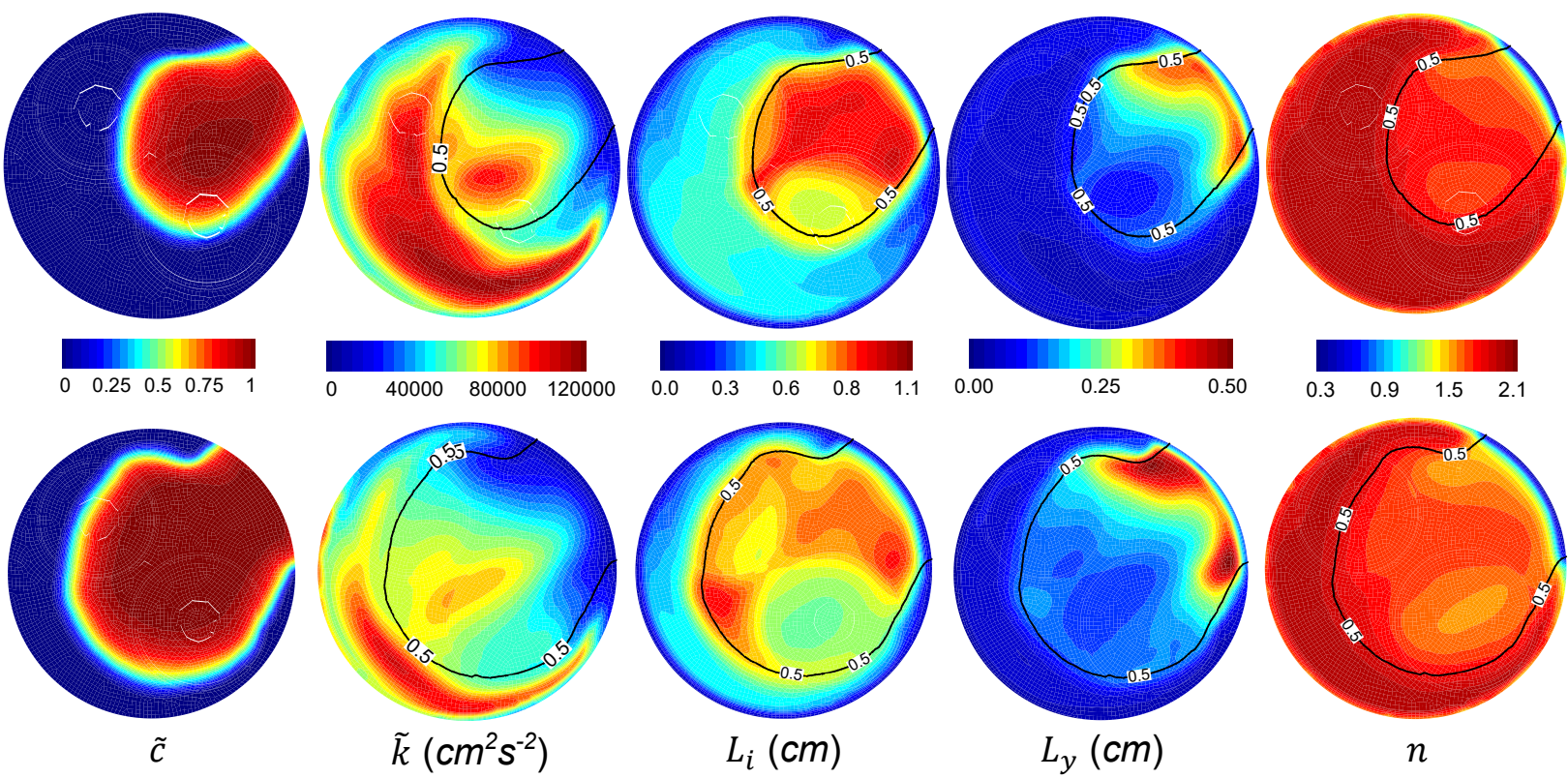

Figure 11: Variation of $M 3$ model parameters at $10^{\circ}$ (first row) and $19^{\circ}$ ATDC (second row) for case 1. $\tilde{c}=0.5$ cuve is superimposed on each figure. 
Simulation of full engine cycle with port flow provides an opportunity to investigate spatial variation of flow properties. Therefore, the variation of some of the M3 model parameters are examined here. Values of $\tilde{c}, \tilde{k}, L_{i}, L_{y}$ and $n$ corresponding to case 1 at $10^{\circ}$ and $19^{\circ}$ ATDC are plotted in Figure 11.

The flame region corresponds to $0<\tilde{c}<1$. Iso-contour $\tilde{c}=0.5$ can be thought as the flame front. It has been superimposed on all figures to indicate the flame position. As all the other parameters plotted here are derived quantities of $\tilde{k}$, their variations are mainly driven by the turbulence kinetic energy. The $\tilde{k}$ value is significantly higher at the unburned region and is greatly reduced in the burned gas region due to viscous dissipation. Temporal variation of $\tilde{k}$ is also noteworthy. It also has very low near walls values due to high viscous dissipation. Hence, the use of classical BML model would have resulted in flame wall acceleration. As per Figure 11, distribution of $L_{i}$ and $L_{y}$ in the unburned side is seem to be uniform, however their spatial variations in the flame region can be seen from Figure 12 and 13". Figure 12 shows temporal evolution of flame front iso surface coloured with flame wrinkling exponent $n$. Figure 13 shows the other model parameters on the flame front at $19^{\circ}$ ATDC. In regions with minimum wall effects, $n$ is close to 2.1 indicating the flow is significantly turbulent. Further, it indicates that $D$ is in its maximum, i.e at 2.3. For this case, during combustion $u^{\prime} / S_{L}$ value is found to be in the order of 3 and consequently the $D$ value is justified [40].

Values of $L_{i}$ and $L_{y}$ depend on relative intensities of $k$ and $\varepsilon$. For example, in the back region of the flame as per Figure 13, low $k$ and low $\varepsilon$ values have resulted in higher $L_{i}$ and $L_{y}$ values. In lower $k$ and higher $\varepsilon$ regions such as near wall regions, $L_{i}$ and $L_{i}$ values are lower. 


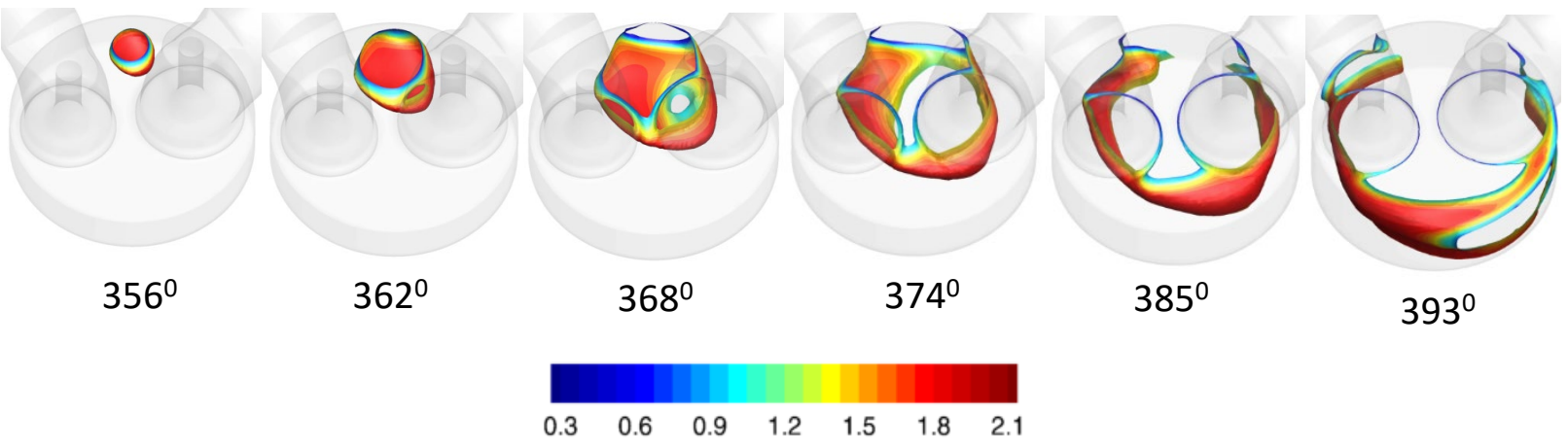

Figure 12: Evolution of $\tilde{c}=0.5$ iso surface for E6 engine case 1. Ignition at $344^{0}$. Flame front contours show local $n$ value.

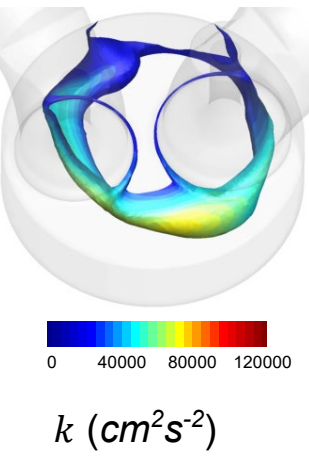

Figure 13:

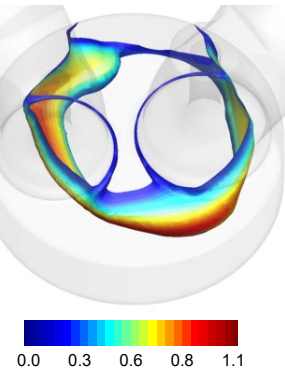

$L_{i}(\mathrm{~cm})$

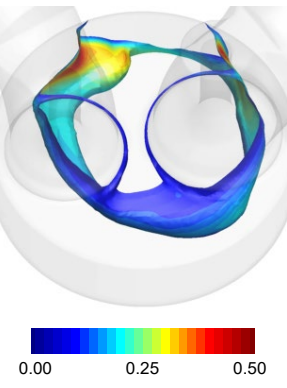

$L_{y}(\mathrm{~cm})$

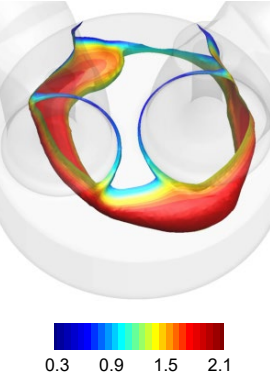

$n$

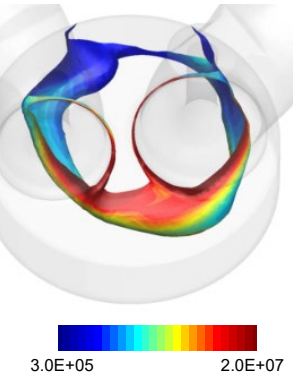

$\varepsilon\left(\mathrm{cm}^{2} \mathrm{~s}^{-3}\right)$

Values of M3 model parameters on the flame front represented by $\tilde{c}=0.5$ iso contour at $19^{\circ}$ ATDC

By $368^{\circ}$, flame deformation due to the bulk flow motion become evident and is clearly seen in figures corresponding to $374^{\circ}$ and $385^{\circ}$. Quenching of flames due to interaction with cylinder wall is shown by $393^{\circ}$. Flame propagation is generally seen to be symmetric about the spark plug location, as commonly seen in flat head flat piston engines, though the flame at exhaust valve side reaches the cylinder wall with a little delay due to the bulk circulating motion of the in cylinder mixture.

Even though the models presented here show a considerable success, the following limitations also exist. The effect of the tumble flow and velocity distribution of the omnipresent wall boundary layer significantly affect the wall quenching phenomenon. Consequently, the accurate modelling 
of boundary layer is important in this regard. The boundary layer model of the present work has been limited to the standard law of the wall model, where the entire boundary layer is assumed to be contained in the first wall cell and the cell flow velocity is approximated using simplified semi empirical correlations. As a result, the true effect of the boundary layer is not evident in the present results. On the other hand, when the flame reaches the wall acoustics waves flame and wall can also affect the flame propagation behavior, which is also not been considered in the present simulations.

\section{CONCLUSIONS}

- Some of the early versions of RANS combustion models, do not consider wall effects on reaction rate calculations, leading to flame wall acceleration problem when applied for wall bounded combustion.

- The work presented here, developed a correlation based on experimental measurements, to account for the reduction in reaction rates near sold walls due to flame quenching.

- The quenching correlation was tested applied to SI engine combustion with the BML model.

- An improved version of the BML model based on KPP analysis and fractal theory was also developed.

- Results, indicate that the quenching rate model combined with the improved BML model has successfully eliminated flame wall acceleration problem.

- Predicted pressure and mass burn rates were also in very good agreement for most of the test cases with an error less than $5 \%$.

- Flame wrinkling exponent $n$ of the BML model is shown to range from 0.8 to 2.1 , whereas this is traditionally taken to be 1.0 . 


\section{ACKNOWLEDGEMENTS}

\section{REFERENCES}

1. BP., 2019. BP Statistical Review, $68^{\text {th }}$ Ed. London, UK.

2. Reitz RD, Ogawa H, Payri R, et al. The future of the internal combustion engine, Editorial. Int. J. Engine Res. 2020; 21:3-10.

3. Daniel WA. Flame quenching at the walls of an internal combustion engine. Symp. (Int) Combust. 1957; 1(6): pp.886-894.

4. Foucher F, Burnel S, Mounaïm-Rousselle C. Evaluation of burning rates in the vicinity of the piston in a spark-ignition engine. Proc Combust Inst. 2002; 29(1):751-757.

5. Foucher F, Mounaïm-Rousselle C. Fractal approach to the evaluation of burning rates in the vicinity of the piston in a spark-ignition engine. Combust Flame. 2005;143(3):323-332.

6. Poinsot TJ, Haworth DC, Bruneaux G. Direct simulation and modeling of flame-wall interaction for premixed turbulent combustion. Combust Flame. 1993;95(1-2):118-132.

7. Demesoukas S, Caillol C, Higelin P, et al. Near wall combustion modeling in spark ignition engines. Part A: Flame-wall interaction. Energy Convers. Manage. 2015; 106:1426-1438.

8. Sellmann J, Lai J, Kempf AM, Chakraborty N. Flame surface density based modelling of headon quenching of turbulent premixed flames. Proc Combust Inst. 2017 ;36(2):1817-1825. 
9. Pashaei J, Saray RK. Development of a quasi-dimensional, fractal-base combustion model for SI engines by simulating flame-wall interaction phenomenon. Fuel. 2019; pp.236:13-29.

10. Bruneaux G, Poinsot T, Ferziger JH. Premixed flame-wall interaction in a turbulent channel flow: budget for the flame surface density evolution equation and modelling. J Fluid Mech. $1997 ; 349: 191-219$.

11. Alshaalan TM, Rutland CJ. Turbulence, scalar transport, and reaction rates in flame-wall interaction. Symp. (Int) Combust. 1998; 27(1): pp. 793-799.

12. Boust B, Sotton J, Labuda SA, et al. A thermal formulation for single-wall quenching of transient laminar flames. Combust Flame. 2007; 149(3):286-294.

13. Gruber A, Sankaran R, Hawkes ER, et al. Turbulent flame-wall interaction: a direct numerical simulation study. J Fluid Mech. 2010; 658:5-32.

14. Lai J, Chakraborty N. Effects of Lewis number on head on quenching of turbulent premixed flames: a direct numerical simulation analysis. Flow Turb Combust. 2016; 96(2):279-308.

15. Suckart D, Linse D. Modelling turbulent premixed flame-wall interactions including flame quenching and near-wall turbulence based on a level-set flamelet approach. Combust Flame. 2018; 190:50-64.

16. Tao $M$, Ge H, VanDerWege $B$, et al. Fuel wall film effects on premixed flame propagation, quenching and emission. Int. J. Engine Res. 2020;21(6):1055-1066.

17. Tao M, Zhao P, VanDerWege B, et al. Further study on wall film effects and flame quenching under engine thermodynamic conditions. Combust Flame. 2020;216:100-110. 
18. Bardis K, Kyrtatos $\mathrm{P}, \mathrm{Xu}$., et al. Development and validation of a novel quasi-dimensional combustion model for un-scavenged prechamber gas engines with numerical simulations and engine experiments. Int. J. Engine Res, Sept 2020 - In Press.

19. Weller HG, Uslu S, Gosman AD, et al. Prediction of combustion in homogeneous-charge spark-ignition engines. Int Sym. COMODIA. 1994; pp.163-169.

20. Watkins AP, Li SP, Cant RS. Premixed combustion modelling for spark-ignition engine applications. SAE Technical Paper: 1996: pp.1614-1626.

21. Abu-Orf GM, Cant RS. A turbulent reaction rate model for premixed turbulent combustion in spark-ignition engines. Combust Flame 2000;122(3):233-252.

22. Nishiwaki K. Modeling engine heat transfer and flame-wall interaction. Int Symp COMODIA 1998; pp.35-44.

23. Jennings MJ. Multi-dimensional modeling of turbulent premixed charge combustion. $S A E$ Technical Paper :1992:1106-1124.

24. Lai J, Chakraborty N, Zhao P, et al. Heat flux and flow topology statistics in oblique and headon quenching of turbulent premixed flames by isothermal inert walls. Combust Sci Technol. 2019; 191(2):353-381.

25. Suckart D, Linse D, Schutting E, et al. Experimental and simulative investigation of flame-wall interactions and quenching in spark-ignition engines. Auto Engine Technol. 2017;2(1-4):2538. 
26. Lavoie GA. Correlations of combustion data for SI Engine calculations-laminar flame speed, quench distance and global reaction rates. SAE Technical Paper:1978, pp. 1015-1033.

27. Westbrook CK, Adamczyk AA, Lavoie GA. A numerical study of laminar flame wall quenching. Combust Flame. 1981:1(40): 81-99.

28. Labuda S, Karrer M, Sotton J, Bellenoue M. Experimental study of single-wall flame quenching at high pressures. Combust Sci Technol. 2011: 183(5): 409-426.

29. Bray KN, Libby PA, Moss JB. Flamelet crossing frequencies and mean reaction rates in premixed turbulent combustion. Combust Sci Technol. 1984;41(3-4): 143-72.

30. Haworth DC, Poinsot TJ. Numerical simulations of Lewis number effects in turbulent premixed flames. J of Fluid Mech. 1992; 244: 405-436.

31. Law CK, Zhu DL, Yu G. Propagation and extinction of stretched premixed flames. Sym (Int) Combust, 1988;21(10): 1419-1426.

32. Gülder ÖL. Correlations of laminar combustion data for alternative SI engine fuels. SAE Technical Paper: 841000.

33. Ranasinghe J, Cant S. A turbulent combustion model for a stratified charged, spark ignited internal combustion engine. SAE Technical Paper: 2000-01-0275, pp. 336-346.

34. Bray KN. Studies of the turbulent burning velocity. Proc $R$ Soc of London, Sec A: Math Phy Sci. 1990;431(1882): 315-335. 
35. Amsden AA, Orourke PJ, Butler TD. KIVA-2: A computer program for chemically reactive flows with sprays. NASA STI/recon technical report N. May 1989.

36. Poinsot T, Veynante D. Theoretical and numerical combustion. RT Edwards; 2005.

37. Matthews RD, Chin YW. A fractal-based SI engine model: comparisons of predictions with experimental data. SAE Technical Paper: 910079, pp. 99-117.

38. Güider ÖL, Smallwood GJ. Do turbulent premixed flame fronts in spark-ignition engines behave like passive surfaces?. SAE Technical Paper: 2000-01-1942, pp. 1823-1832.

39. Peters N. The turbulent burning velocity for large-scale and small-scale turbulence. $J$ Fluid Mech 1999; 384:107-132.

40. North GL, Santavicca DA. The fractal nature of premixed turbulent flames. Combust Sci Technol 1990;72(4-6):215-232.

41. Kuo TW, Reitz RD. Computation of premixed-charge combustion in pancake and pent-roof engines. SAE Technical Paper: 890670, pp.1239-1257.

42. Torres DJ, Trujillo MF. KIVA-4: An unstructured ALE code for compressible gas flow with sprays. J Comput Phys 2006; 10:219(2):943-975.

43. Fan L, Reitz RD. Development of an ignition and combustion model for spark-ignition engines. SAE Technical Paper: 2000-01-2809, pp. 1977-1989.

44. Tan Z, Reitz RD. Modeling ignition and combustion in spark-ignition engines using a level set method. SAE Technical Paper: 2003-01-0722, pp. 1028-1240. 
45. Ranasinghe CP. Development of combustion models for RANS and LES applications in SI engines. PhD Thesis, Loughborough University, UK, 2013.

46. Ramshaw JD. Partial chemical equilibrium in fluid dynamics. Phys Fluids 1980;23(4):675-80.

47. Zhao H, Collings $\mathrm{N}$, Ma T. The cylinder head temperature measurement by thermal imaging technique. SAE Technical Paper: 912404, pp. 863-876. 